\title{
Experimental Investigation into the Effects of Fracturing Fluid-Shale Interaction on Pore Structure and Wettability
}

\author{
Yan Zhang, ${ }^{1,2}$ Zhiping Li ${ }^{1,2}$, Fengpeng Lai, ${ }^{1,2}$ Hao Wu, ${ }^{1}$ Gangtao Mao, ${ }^{1,2}$ \\ and Caspar Daniel Adenutsi ${ }^{3}$ \\ ${ }^{1}$ School of Energy Resources, China University of Geosciences, Beijing 100083, China \\ ${ }^{2}$ Beijing Key Laboratory of Unconventional Natural Gas Geological Evaluation and Development Engineering, China University \\ of Geosciences, Beijing 100083, China \\ ${ }^{3}$ Core and Rock Properties Laboratory, Department of Petroleum Engineering, Faculty of Civil and Geo-Engineering, \\ Kwame Nkrumah University of Science and Technology, Kumasi, Ghana
}

Correspondence should be addressed to Zhiping Li; 2002011671@cugb.edu.cn

Received 15 October 2020; Revised 5 December 2020; Accepted 27 March 2021; Published 14 April 2021

Academic Editor: Ruud Weijermars

Copyright (c) 2021 Yan Zhang et al. This is an open access article distributed under the Creative Commons Attribution License, which permits unrestricted use, distribution, and reproduction in any medium, provided the original work is properly cited.

\begin{abstract}
One of the main techniques for the exploitation of shale oil and gas is hydraulic fracturing, and the fracturing fluid (slick water) may interact with minerals during the fracturing process, which has a significant effect on the shale pore structure. In this study, the pore structure and fluid distribution of shale samples were analyzed by utilizing low-pressure liquid nitrogen adsorption (LP-N $\mathrm{N}_{2} \mathrm{GA}$ ) and nuclear magnetic resonance (NMR). The fractal analysis showed that the pore structure of the sample was strongly heterogeneous. It was also found that the effect of slick water on pore structure can be attributed to two phenomena: the swelling of clay minerals and the dissolution of carbonate minerals. The swelling and dissolution of minerals can exist at the same time, and the strength of them at different soaking times is different, leading to the changes in specific surface area and pore size. After the samples were soaked in the slick water for two days, the contact angle reached the minimum value (below $8^{\circ}$ ), which means the sample is strongly hydrophilic; then the contact angle increased to above $38^{\circ}$ with longer soaking times. The connected pore space in the shale matrix is enlarged by the soaking processing. Therefore, an in-depth understanding of the interaction between the fracking fluid and shale is essential to deepen our understanding of changes in the pore structure in the reservoir and the long-term productivity of shale gas.
\end{abstract}

\section{Introduction}

In recent years, the relative lack of conventional gas resources has made shale gas popular and the exploitation of shale gas resources has become essential to meet demand. The shale gas resources in China are abundant, and the recoverable volume is estimated to be about 261012 cubic meters [1-3]. Shale gas refers to the gas in shale pores and adsorbed in the matrix [4-6]; thus, understanding the characteristics of shale gas reservoirs is very important for efficient exploitation. Pores in shale gas reservoirs are dominated by nanopores, resulting in lower porosity and permeability [7-9], which necessitates the use of advanced fracturing technology during the exploitation. The hydraulic fracturing of the reservoir forms more connecting fracture networks which increase the production of shale gas [10]. Slick water fracturing fluid (commonly called slick water) is mainly used for hydraulic fracturing of shales because it is efficient and cheap [11-13].

Commonly, large volumes of water-based fracturing fluids are injected into the reservoir during the fracturing process. However, there is a large difference between the volume of slick water injected and flowback, which means a lot of slick water remains trapped in the reservoir and will react with the shale matrix [14-16]. The interaction between slick water and shale may have a great impact on the storage and flow of shale gas $[15,17-19]$. Therefore, an in-depth understanding of the interaction between the fracking fluid and shale is essential to deepen our understanding of changes in the pore structure in the reservoir and the long-term 
productivity of shale gas $[17,19,20]$. In addition to organic matter, shale also contains clay minerals, carbonate, and brittle minerals [21]. The clay content in shale is often an important factor affecting shale gas flow capacity, which is due to the swelling of clay when exposed to water [22-25]. The study of Pedlow and Sharma [23] indicated that the high clay content (over 20\%) in shale can reduce the fracture conductivity in $3.5 \%$ salty water. Wu and Sharma [26] studied the effects of acid fracturing on carbonate-rich shale; they reported that acid fracturing will increase the fracture conductivity. Besides, the wettability of shale is also critical to shale gas production, which is related to the imbibition of fracturing fluid and the possible water blocking effect, which has an important effect on the fluid transport process $[16,27]$. Prior researches have been done on the reaction principles of slick water and shale matrix, and it was found that the swelling of clay minerals and dissolution of carbonate minerals cause changes in pore structures of shale reservoirs $[14,23,24]$. Understanding how slick water changes pore structure and physical properties is essential for the design and application of fracturing [26], and the effects of slick water-shale interaction on pore structure and physical properties need further discussion [28].

There are many common techniques for studying pore structure, such as low pressure nitrogen gas adsorption (LP-N $\left.\mathrm{N}_{2} \mathrm{GA}\right)[4,29,30]$, mercury injection capillary pressure (MICP) [31, 32], computed tomography (CT) [33-35], scanning electron microscope (SEM) [36, 37], small-angle neutron scattering (SANS) [38], and nuclear magnetic resonance (NMR) $[30,39,40]$. All of these techniques have their advantages and disadvantages. Among them, LP-N 2 GA and NMR have been widely applied to the study of unconventional reservoir rocks to characterize the nanopores. A fractal theory was applied to study the extremely complex shale pore structure, while the fractal characteristics of the pore structure are believed to be related to the adsorption and seepage capacity [21-24]. Fractal theory can be combined with a variety of experimental methods for data processing, such as the thermodynamic model, the model based on MICP, and the Frenkel-Halsey-Hill (FHH) model based on the LP- ${ }_{2}$ GA experiment $[30,41]$, which is a simple and fast method used to obtain the fractal dimension of shale [42].

In this work, the LP- $\mathrm{N}_{2} \mathrm{GA}, \mathrm{NMR}$, wettability, and X-ray diffraction (XRD) experiments were utilized to analyze the dynamic influence of slick water on shale pore structure in this study. This paper can be divided into three sections. Firstly, experimental design including a description of samples as well as experimental procedures was introduced. Secondly, the fractal theory model was established. Finally, the influence of slick water on pore structure and wettability was discussed. Especially, the dynamic change of wettability and pore structure with the reaction time of slick water was explored, which is believed to be meaningful for shale gas exploitation.

\section{Method}

2.1. Samples. The shale samples were collected from the Youke Well located in Chongqing, China. The average per- meability and porosity were $0.0046 \mathrm{mD}$ and $4.5 \%$, respectively. Four core samples (Nos. 1-4) were drilled from the same large block of shale for the NMR experiment and wettability test. Crushed samples were taken from the places where the four core samples were drilled for LP-N ${ }_{2}$ GA experiments. A total of 15 mixed crushed samples were obtained for LP- $\mathrm{N}_{2} \mathrm{GA}$ analysis; 4 core plugs were used for wettability and NMR experiments. The composition of the slick water used in experiments was $0.05 \%$ thickener, $1 \% \mathrm{KCl}, 0.8 \%$ $\mathrm{pH}<3$ cross-linking agent (containing $\mathrm{HCl}$ ), and $0.1 \%$ clean-up additive.

\subsection{Experiments}

2.2.1. $L P-N_{2} G A$ Experiment. The LP-N ${ }_{2}$ GA experiment was carried out using the $3 \mathrm{H}-200 \mathrm{PS} 1$ analyzer. The details about these instruments can be found in the previous study [30]. The specific experimental procedures are as follows: (1) 8 crushed samples weighing $5 \mathrm{~g}$ each were soaked in slick water for $0 \mathrm{~h}, 6 \mathrm{~h}, 12 \mathrm{~h}, 1$ day, 2 days, 4 days, 6 days, and 8 days at $30^{\circ} \mathrm{C}$ and atmospheric pressure; (2) the crushed samples were dried and sieved with 40-mesh size; and (3) $1.85 \mathrm{~g}$ of each powder sample was taken for LP-N ${ }_{2} \mathrm{GA}$ experiments. The LP-N $\mathrm{N}_{2} \mathrm{GA}$ experiment measurement method was mainly used for studying the specific surface area (SSA) and pore volume (PV) of the sample.

The SSA was determined by linear regression using the multipoint Brunauer-Emmett-Teller (BET) method (Equation (1)), while the pore size distribution (PSD) was obtained by the Barrett-Joyner-Halenda (BJH) desorption method $[43,44]$.

$$
\frac{V}{V_{m}}=\frac{C \times P}{\left(P_{0}-P\right)\left[1+(C-1)\left(P / P_{0}\right)\right]},
$$

where $V$ is the adsorption amount, $P$ is the gas adsorption equilibrium pressure, $P_{0}$ is the saturated vapor pressure, $V_{m}$ is the maximum monolayer adsorption capacity, and $C$ is the constant associated with adsorption heat.

Equation (1) can be changed into

$$
\frac{P}{V\left(P_{0}-P\right)}=\frac{C-1}{C V_{m}} \times \frac{P}{P_{0}}+\frac{1}{C V_{m}} .
$$

By graphing $P /\left(V\left(P_{0}-P\right)\right)$ and $P / P_{0}$, we can get a straight line with a slope and intercept of $C-1 / C V_{m}$ and $1 / C V_{m}$, respectively, so that the values of the constants $C$ and $V_{m}$ can be obtained.

The specific surface area can be calculated according to the following equation:

$$
\mathrm{SSA}=\frac{V_{m}}{22400} N_{A} \sigma_{m}
$$

where SSA is the specific surface area, $\sigma_{m}$ is the crosssectional area of the adsorbed molecule, and $N_{A}$ is the Avogadro constant. 
TABLE 1: Change of composition after slick water soaking.

\begin{tabular}{lccccccc}
\hline Sample & Quartz & Potash feldspar & Plagioclase & Calcite & Dolomite & Pyrite & Clay mineral \\
\hline J-0 & $22.1 \%$ & $0.9 \%$ & $4.5 \%$ & $2.7 \%$ & $60.2 \%$ & $2.7 \%$ & $6.9 \%$ \\
J-8 & $22.1 \%$ & $0.9 \%$ & $4.5 \%$ & $2.5 \%$ & $58.4 \%$ & $2.7 \%$ & $7.3 \%$ \\
\hline
\end{tabular}

The basic principle of $\mathrm{BJH}$ is based on capillary condensation by combining the Kelvin equation (Equation (4)) with experimental data.

$$
\ln \frac{P}{P_{0}}=\frac{2 \gamma M}{R T \rho} \times+\frac{1}{r}
$$

where $\gamma$ is surface tension, $M$ is molar mass, $\rho$ is liquid density, and $r$ is the corresponding pore radius. However, the $r$ is not the real pore radius because the thickness of the adsorption layer is not taken into account. Therefore, according to $\mathrm{BJH}$ theory, the thickness of the adsorption layer is considered, so that a more accurate PSD is obtained.

2.2.2. NMR Experiment. The NMR experiment was carried out using SPEC-RC1. And the NMR experiments were designed to investigate the influence of slicking water soaking on the changes in the pore size of the sample. Thus, the NMR T2 spectrum was measured after the samples were saturated for a cumulative period of $1,2,4$, and 8 days with slick water at $30^{\circ} \mathrm{C}$ and $20 \mathrm{MPa}$. Before the NMR experiment, the four core samples were dried at the temperature of $105^{\circ} \mathrm{C}$, dried for $24 \mathrm{~h}$. The specific experimental procedures are as follows: (1) measuring the contact angles of the samples at $30^{\circ} \mathrm{C}$ and atmospheric pressure; (2) drying the samples at $105^{\circ} \mathrm{C}$ for $24 \mathrm{~h}$; (3) vacuuming the samples for $12 \mathrm{~h}$ and then saturated with slick water for $24 \mathrm{~h}$ at $30^{\circ} \mathrm{C}$ and $20 \mathrm{MPa}$; and (4) measuring the NMR T2 spectrum of all the fully saturated samples at $30^{\circ} \mathrm{C}$ and atmospheric pressure.

Low field NMR technology can be used to analyze the PSD of samples by detecting the amount of fluid in pores according to the following equation [32]:

$$
\frac{1}{T_{2}}=\rho_{2} \frac{S}{V},
$$

where $T_{2}$ is the surface transverse relaxation time (ms), $\rho_{2}$ is transverse relaxation strength, and $S / V$ refers to the surfaceto-volume ratio. If the pore shapes are reduced to tube or spherical balls, $S / V$ can be reduced to parameters related to the pore radius, so $T_{2}$ can be associated with PSD.

2.2.3. Contact Angle Measurement. In this study, the contact angle was also measured by employing an instrument produced by USA KINO Industry Co., Ltd. The instrument was mainly composed of an optical system including a light-emitting diode (LED) light source, a high-speed camera, and a magnifying lens. The automatic injection pump is used to inject the liquid onto the sample, and the contact angle is measured by the tangent method. The wettability of the sample can be then determined by measuring the contact angle through the image. To reduce the effects of heterogene-

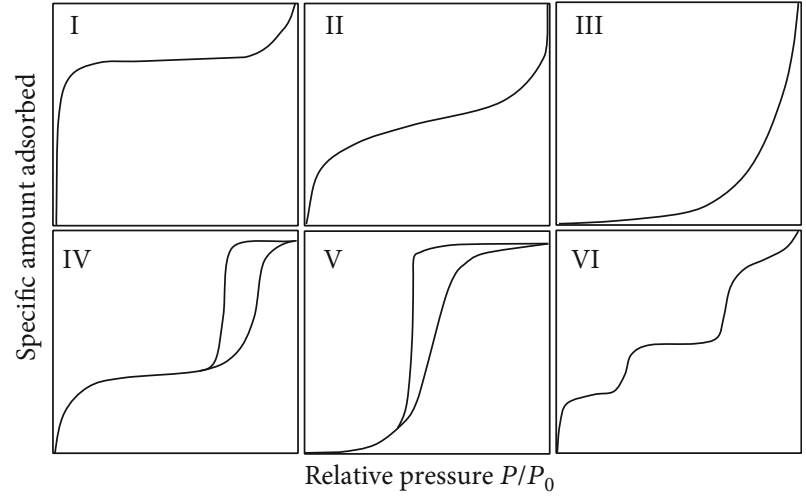

Figure 1: Classification of adsorption isotherm [56].

ity, each sample was tested 20 times, averaging as the final contact angle. The whole experimental process was carried out at $30^{\circ} \mathrm{C}$ and atmospheric pressure.

\section{Fractal Theory}

Mandelbrot and Wheeler [45] proposed the fractal theory, which has been widely applied in rock physics analysis. Recent developments in fractal theory make it possible to apply MICP, LP- $\mathrm{N}_{2} \mathrm{GA}$, SEM, and XRD methods to conduct in-depth studies of the fractal properties of rocks [30, 42, 46]. In this study, the Frenkel-Halsey-Hill (FHH) model was utilized to analyze the and pore complexity and irregularity based on $\mathrm{LP}-\mathrm{N}_{2} \mathrm{GA}$ data [47]. Here is the mathematical expression of the FHH model [42]:

$$
\ln V=\text { Const }+K \cdot \ln \left(\ln \left(\frac{P_{0}}{P}\right)\right)
$$

where $V$ represents the adsorption capacity of nitrogen at equilibrium pressure $P$ and $P_{0}$ is the saturated vapor pressure.

In the FHH model, parameter $K$ is equal to $(D-3) / 3$ or $D-3$ when van der Waals or surface tension dominates, respectively $[48,49]$, where $D$ is the fractal dimension. Zhang et al. [50] reported that $K=(D-3) / 3$ is only established if capillary force can be completely ignored, and thus, $K=$ $D-3$ should be used because capillary force played a significant role during nitrogen adsorption. Besides, $K=D-3$ has been successfully used to study the fractal characteristics of unconventional reservoir rocks $[46,51]$.

In general, the value of $D$ is between 2 and 3 , where the pore surface is perfectly smooth if $D=2$ and $D=3$ represents an extremely complex surface [52]. The increase in the 


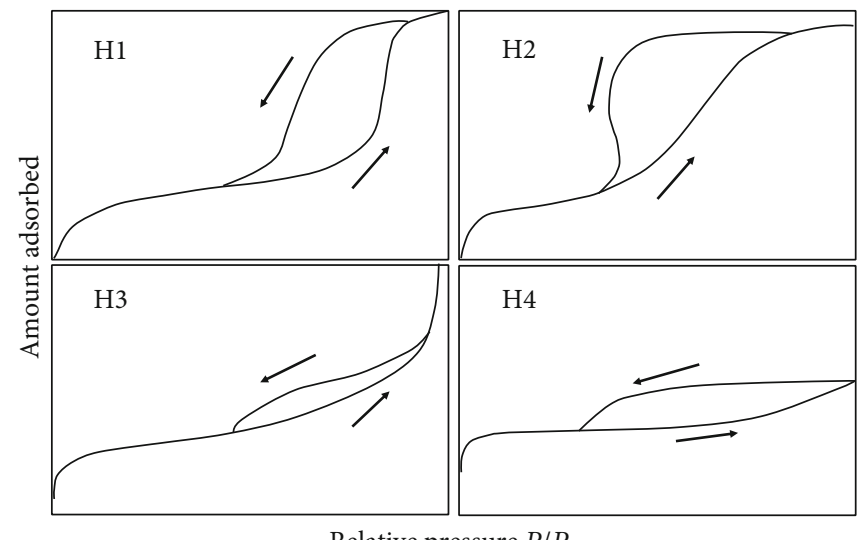

Figure 2: IUPAC classification of hysteresis loops [47].
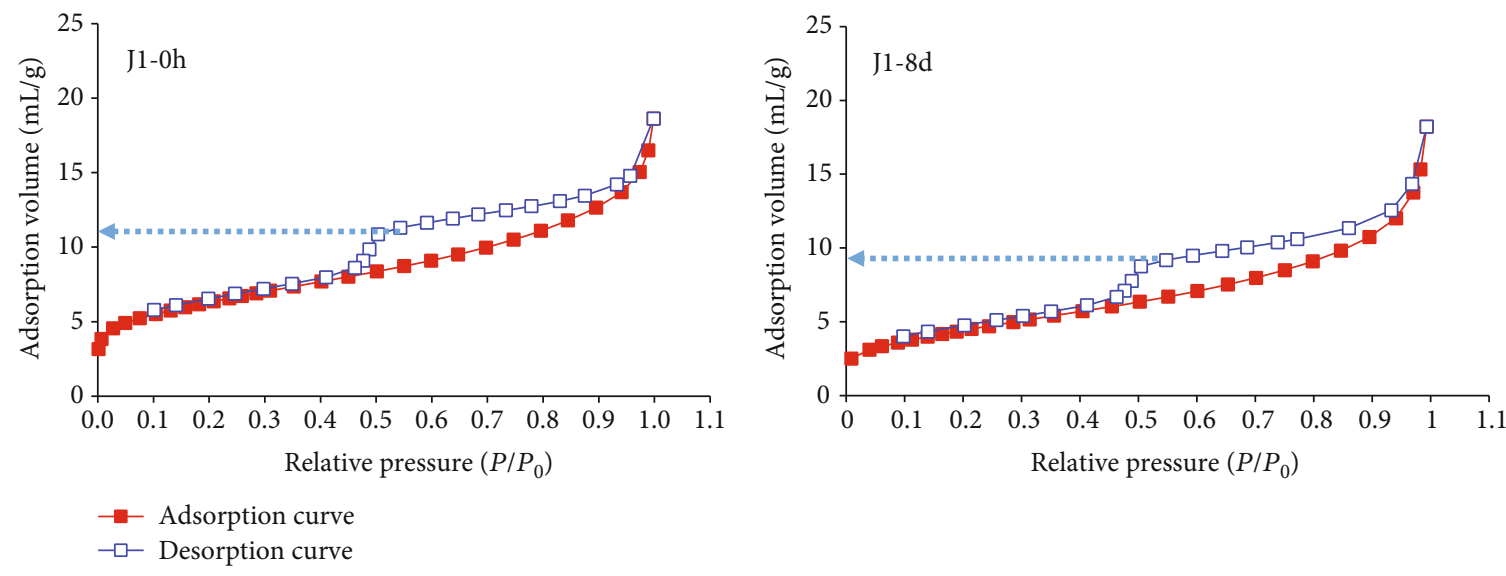

FIGURE 3: Low-pressure nitrogen sorption isotherms of shale soaked in slick water for different times.

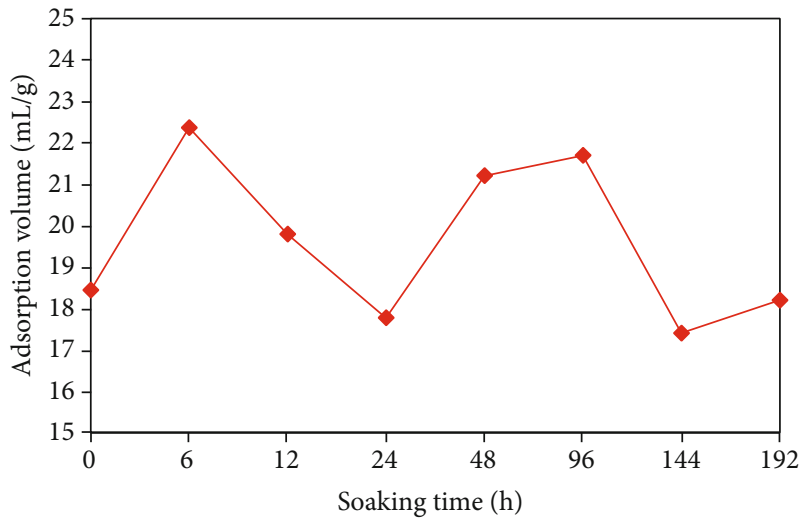

FIgURE 4: Change of nitrogen adsorption volume for different soaking times.

value of $D$ from 2 to 3 represents an increase in the irregularity and complexity of the pores. $K$ has different values when $P / P_{0}<0.5$ and $P / P_{0}>0.5$, corresponding to two different $D$ values: $D_{1}$ and $D_{2}[46,53]$. According to previous studies, $P / P_{0}<0.5$ and $P / P_{0}>0.5$ represent the adsorption

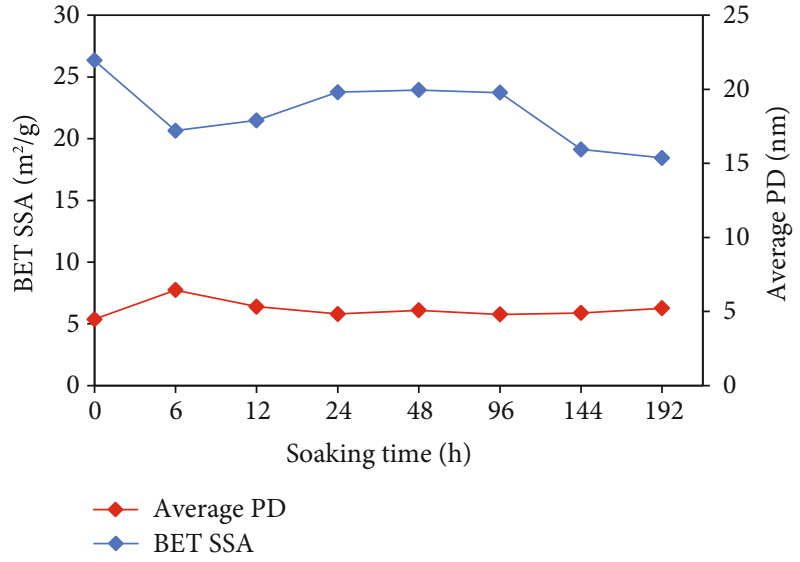

FIgURE 5: Change in pore ratio SSA $\left(\mathrm{m}^{2} / \mathrm{g}\right)$ and average PD $(\mathrm{nm})$ of the sample after soaking in slick water.

process within the pores with $\mathrm{PD}<4 \mathrm{~nm}$ and $\mathrm{PD}>4 \mathrm{~nm}$, respectively $[46,54]$. Therefore, $D_{1}$ and $D_{2}$ represent the irregularity and complexity of the pores with $\mathrm{PD}<4 \mathrm{~nm}$ and $\mathrm{PD}>4 \mathrm{~nm}$, respectively [53]. 

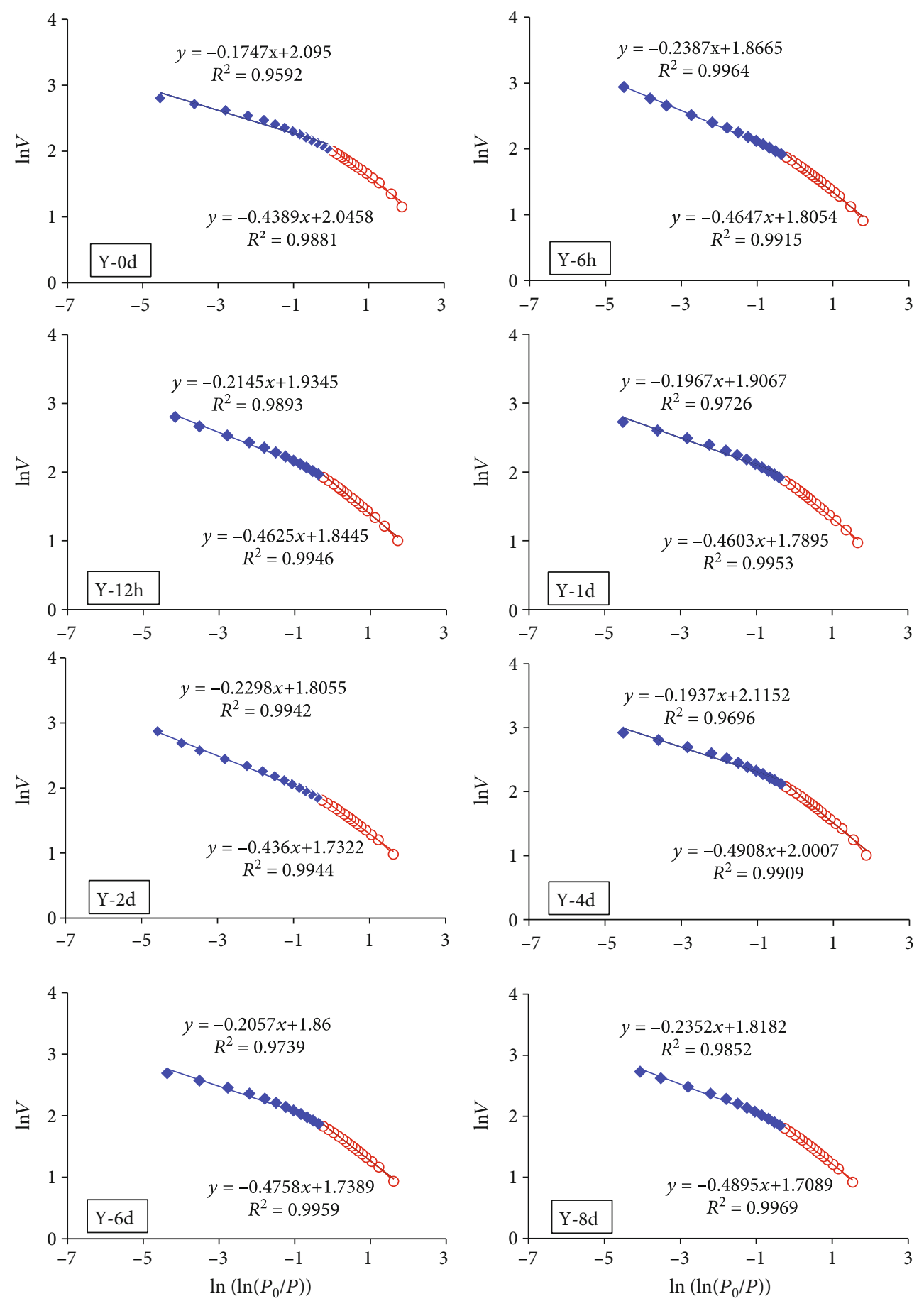

Figure 6: $\ln V$ vs. $\ln \left(\ln \left(P_{0} / P\right)\right)$ from LP-N 2 GA analyses of samples soaked in slick water for different times.

\section{Results and Discussion}

4.1. Influence of Slick Water on Composition. According to the XRD analysis (Table 1 ), the rock sample (J-0) was composed of dolomite $(60.2 \%)$, quartz $(22.1 \%)$, clay minerals $(6.9 \%)$, plagioclase $(4.5 \%)$, calcite $(2.7 \%)$, pyrite $(2.7 \%)$, and potassium feldspar (0.9\%). After 8 days of soaking, XRD results showed that the proportion of clay minerals increased to $7.3 \%$, while the proportion of calcite and dolomite decreased to $2.5 \%$ and $58.4 \%$, respectively. Meanwhile, montmorillonite in shale has a special structure of interlayer pairs, which will swell after being exposed to water [23]. Thus, the clay content has increased by $0.4 \%$ after being soaked in slick water.

The dolomite and calcite in the shale will have the following chemical reaction with acid fracturing fluid:

$$
\mathrm{CaCO}_{3}+2 \mathrm{H}^{+} \longrightarrow \mathrm{Ca}^{2+}+\mathrm{CO}_{2}+\mathrm{H}_{2} \mathrm{O}
$$


TABLE 2: Fractal dimensions of samples soaked in slick water for different times.

\begin{tabular}{lcccccc}
\hline Sample & \multirow{2}{*}{ Soaking time (h) } & \multicolumn{2}{c}{$P / P_{0}<0.5$} & \multicolumn{2}{c}{$P / P_{0}>0.5$} \\
$D_{2}=K_{2}+3$ & $R_{2}$ & $R^{2}$ \\
\hline J-0 & 0 & -0.4389 & 2.5611 & 0.9881 & -0.1747 & 2.8253 \\
J-6 h & 6 & -0.4647 & 2.5353 & 0.9915 & -0.2387 & 2.7613 \\
J-12 h & 12 & -0.4625 & 2.5375 & 0.9946 & -0.2145 & 2.7855 \\
J-1d & 24 & -0.4603 & 2.5397 & 0.9953 & -0.1967 & 2.8033 \\
J-2 d & 48 & -0.436 & 2.564 & 0.9944 & -0.2298 & 2.7702 \\
J-4 d & 96 & -0.4908 & 2.5092 & 0.9909 & -0.1937 & 2.8063 \\
J-6 d & 144 & -0.4758 & 2.5242 & 0.9959 & -0.2057 & 0.9893 \\
J-8 d & 196 & -0.4895 & 2.5105 & 0.9969 & -0.2352 & 0.9942 \\
\hline
\end{tabular}

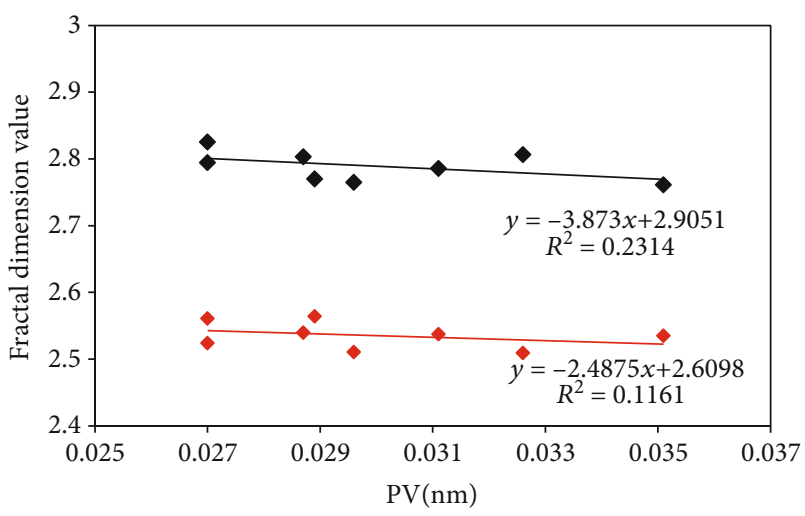

$\bullet \mathrm{D} 1$

$\bullet \mathrm{D} 2$

Figure 7: Relationship between fractal dimensions and PV.

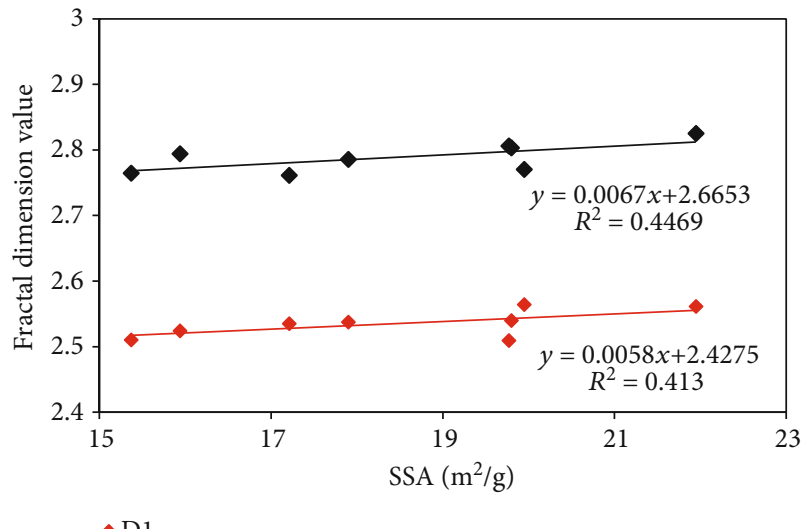

$\bullet$ D1

FIgURE 8: Relationship between fractal dimensions and SSA.

$\mathrm{CaMg}\left(\mathrm{CO}_{3}\right)_{2}+4 \mathrm{H}^{+} \longrightarrow \mathrm{Ca}^{2+}+\mathrm{Mg}^{2+}+2 \mathrm{CO}_{2}+2 \mathrm{H}_{2} \mathrm{O}$.

Due to the reaction, the dolomite and calcite will be dissolved and some small pores would be created.

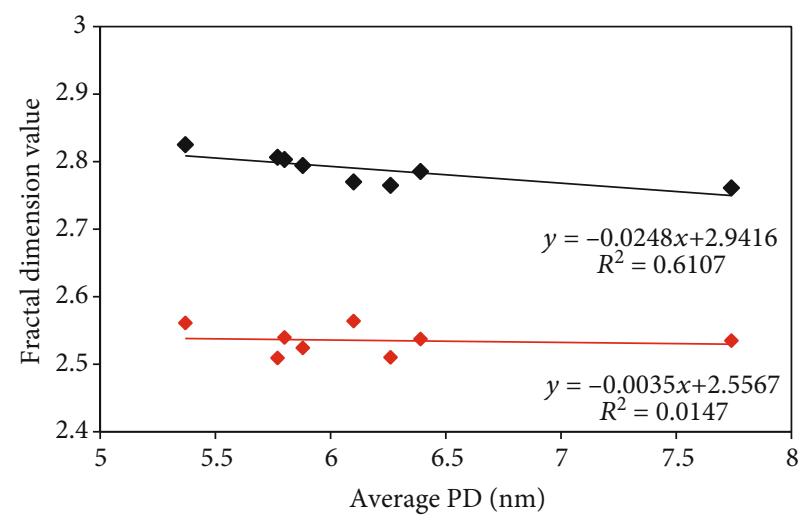

$\bullet$ D1

$\bullet \mathrm{D} 2$

FIgURE 9: Relationship between fractal dimensions and average PD.

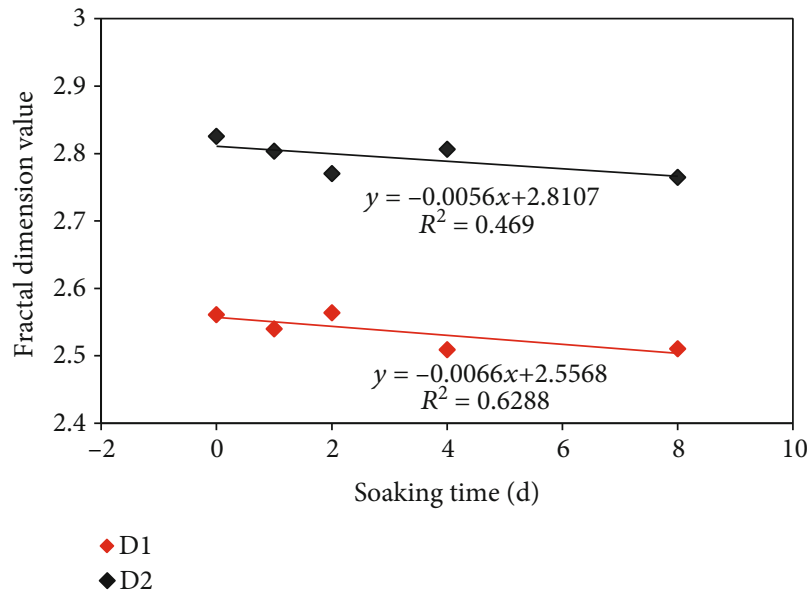

FIgURE 10: Relationship between fractal dimensions and slick water soaking time.

\subsection{Influence of Slick Water on Pore Structure}

4.2.1. Pore Morphology. In the LP- $\mathrm{N}_{2} \mathrm{GA}$ experiment, Y0 represents unsoaked samples; J-6 h, J-12 h, J-1 d, J-2 d, J-4 d, and $\mathrm{J}-8 \mathrm{~d}$ represent samples that are soaked in slick water 


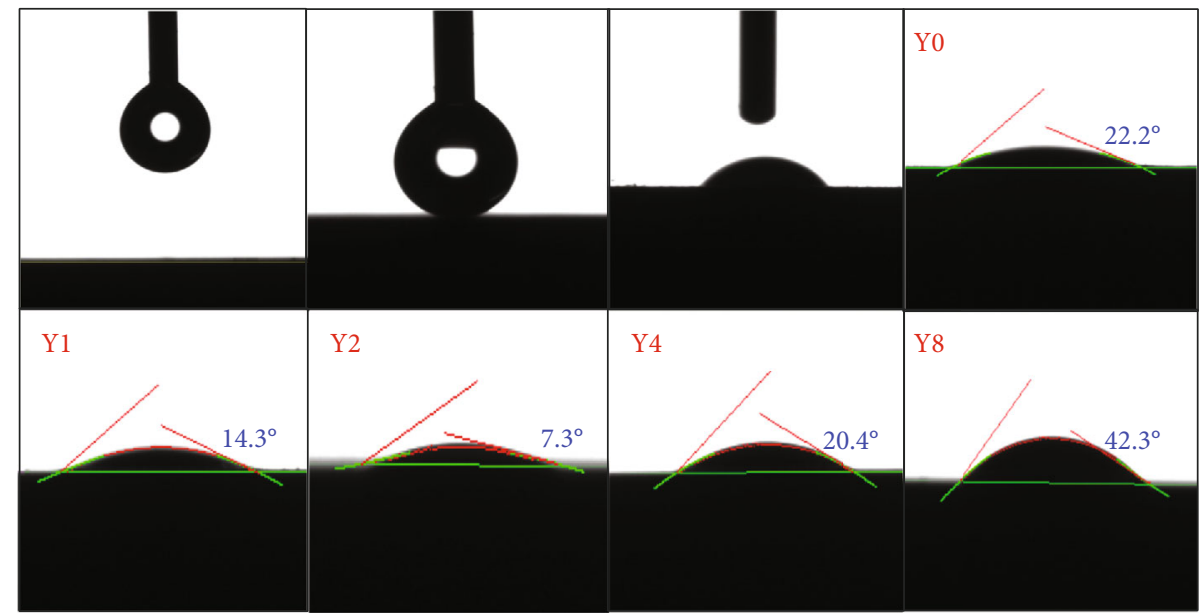

FIGURE 11: Contact angle of sample N0. 1 saturated with slick water for 1, 2, 4, and 8 days.

for 6 hours, 12 hours, 1 day, 2 days, 4 days, and 8 days, respectively. Three different types of pores are classified by combining the International Union of Theoretical and Applied Chemistry (IUPAC) standard and the Hodote classification method based on pore diameter (PD): micropores $(2 \mathrm{~nm} \leq \mathrm{PD} \leq 10 \mathrm{~nm})$, mesopores $(10 \mathrm{~nm} \leq \mathrm{PD} \leq 100 \mathrm{~nm})$, and macropores $(\mathrm{PD}>100 \mathrm{~nm})[9,47,55]$. Sing proposed 6 different types of nitrogen adsorption isotherms (Figure 1) [56], and the IUPAC further classified hysteresis loops into 4 categories (Figure 2) [47]. According to the classification, type $\mathrm{H} 1$ represents cylindrical pores, and type $\mathrm{H} 2$ corresponds to "ink bottle" pores and interparticle pores, while type H3 represents plate-shaped and slit-shaped pores [56] and type $\mathrm{H} 4$ represents micropores with low adsorption capacity [57].

According to the IUPAC classification of hysteresis loops (Figure 2), the pore type of the sample in this study is type $\mathrm{H} 3$, which are plate-like and slit pores. The shape of the adsorption/desorption curves after slick water soaking did not change significantly (Figure 3 ), which indicated that the pore shape changes little before and after the shale samples were soaked in slick water. Furthermore, from Figure 4, it was observed that the nitrogen adsorption volume increased when the sample was soaked in slick water for the first 6 hours, after which the nitrogen adsorption volume continues to decrease from 6 hours to 1 day of soaking. After that, the nitrogen adsorption amount reaches its maximum on day 4 and minimum on day 6 . Since the nitrogen adsorption capacity mainly depends on the volume of connected pores, the change of the LP- $\mathrm{N}_{2} \mathrm{GA}$ volume was related to the change in the volume of connected pores. Therefore, we can conclude that the maximum volume of connected pores is reached in the sixth hour, which is the result of mineral dissolution. Subsequently, the volume of connected pores decreased due to the swelling of clay minerals (6-24 hours). Then, mineral dissolution dominated again, resulting in the increase of connected pore volume (24-96 hours). The connected pore volume decreased due to mineral precipitation (96-144 hours).
TABLE 3: Contact angle after slick water soaking for different times.

\begin{tabular}{lcccc}
\hline Sample & No. 1 & No. 2 & No. 3 & No. 4 \\
\hline Y0 & $22.2^{\circ}$ & $19.3^{\circ}$ & $25^{\circ}$ & $21.4^{\circ}$ \\
Y1 & $14.3^{\circ}$ & $15.7^{\circ}$ & $11.5^{\circ}$ & $7.9^{\circ}$ \\
Y2 & $7.3^{\circ}$ & $4.9^{\circ}$ & $4.9^{\circ}$ & $2.4^{\circ}$ \\
Y4 & $20.4^{\circ}$ & $24.5^{\circ}$ & $35.4^{\circ}$ & $32.4^{\circ}$ \\
Y8 & $42.3^{\circ}$ & $38.4^{\circ}$ & $45.6^{\circ}$ & $51.5^{\circ}$ \\
\hline
\end{tabular}

4.2.2. Specific Surface Area and Pore Size Distribution. From Figure 5, we can find that SSA decreased in the first 6 hours of slick water soaking, and then SSA increased from 6 hours to 24 hours of soaking; SSA did not change from 24 hours to 96 hours, and then SSA decreased from 96 hours of soaking. The SSA is related to the pore shape and pore size; we have proved that the pore shape did not change after being soaked in the slick water; therefore, the change of SSA is caused by the change of pore size. The greater the pore size, the smaller the SSA. Therefore, we can infer that the pore size reaches its maximum due to mineral dissolution in the first 6 hours, followed by the decrease in pore size caused by clay minerals swelling; then the pore size increased again due to the mineral dissolution. This is consistent with the previous analysis. This also shows that mineral dissolution and swelling exist at the same time; the strength of them at different times is different, leading to the changes of SSA and PD.

4.2.3. Fractal Analysis. The FHH fractal model was used to obtain the fractal dimension $(D)$. From Figure 6, it can be observed that two distinct linear sections were established by $P / P_{0}<0.5$ and $P / P_{0}>0.5$. In this paper, $K_{1}$ and $D_{1}$ as well as $K_{2}$ and $D_{2}$ were used to represent the slope and the corresponding fractal dimensions corresponding to $P / P_{0}<0.5$ and $P / P_{0}>0.5$, respectively. Based on Equation (6) and the fitted linear equations in Figure 6, fractal dimensions of samples soaked in slick water for different times were obtained (Table 2). 


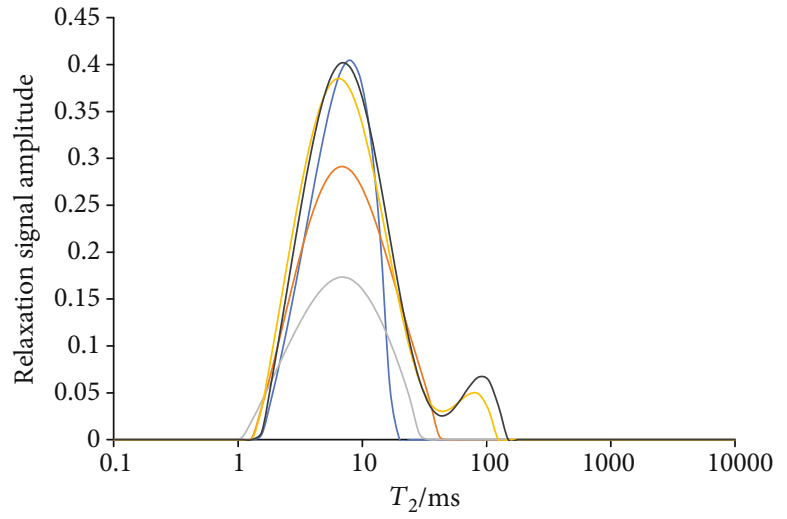

(a)

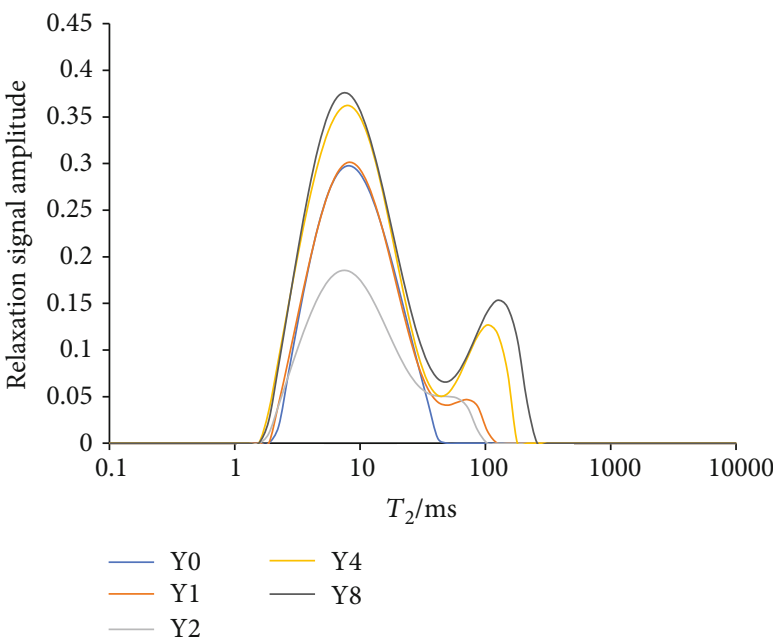

(c)

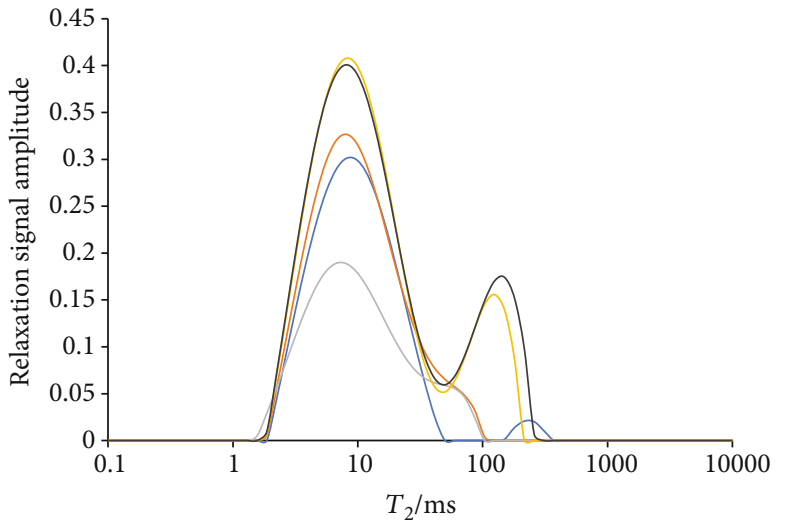

(b)

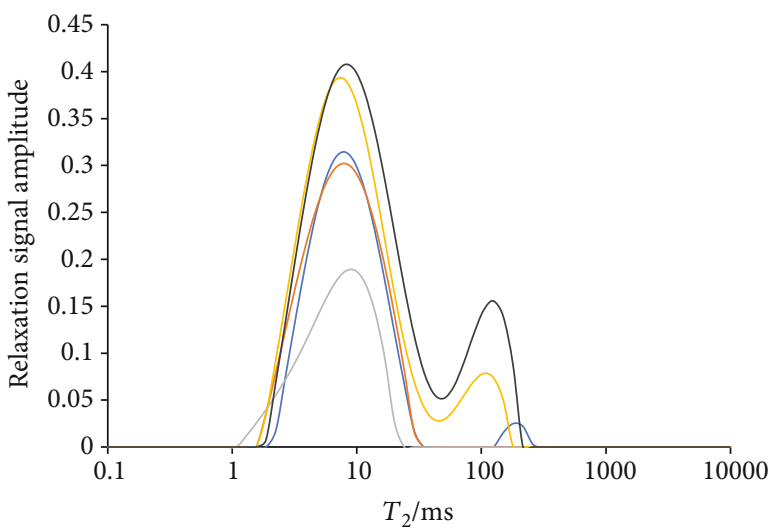

(d)

FIGURE 12: NMR T2 spectrum of four samples saturated with slick water for 1, 2, 4, and 8 days.

The average value of $D_{1}$ was about 2.53 while that of $D_{2}$ was 2.85. According to a previous study, $D_{1}$ and $D_{2}$ represent the irregularity and complexity of the pores with $\mathrm{PD}<4 \mathrm{~nm}$ and $\mathrm{PD}>4 \mathrm{~nm}$, respectively $[42,53]$. This indicates that the irregularity and complexity of the pores with $\mathrm{PD}>4 \mathrm{~nm}$ are greater than that of pores with $\mathrm{PD}<4 \mathrm{~nm}$.

By fitting the $D_{1}$ and $D_{2}$ with PV, SSA, average PD, and soaking time, the linear relationship between these parameters was obtained (Figures $7-10$ ). It can be seen that $D_{1}$ has a better correlation with the average PD (Figure 9), $R^{2}$ of the trendline between $D_{1}, D_{2}$, and SSA are similar (Figure 8), and there is no obvious linear relationship between the PV and $D$ (Figure 7). From Figure 10, it was observed that the relationship between $D_{1}$ and soaking time was better than that of $D_{2}$.

4.3. Influence of Slick Water on Wettability. The changes in the contact angles of the samples after being soaked in slick water for different times are given in Figure 11 (Sample 1 as an example). The changes in the contact angle of all the samples are given in Table 3, where Y0 refers to the original sample and Y1, Y2, Y4, and Y8 represent shale samples after being soaked in slick water for 1,2, 4, and 8 days, respectively.
The contact angles of the shale samples changed continuously when the samples were soaked in slick water. The contact angle appeared to be minimum when it was soaked in slick water for two days. The contact angle reaches its minimum value on the second day because the reaction between slick water and the minerals results in a change in the surface properties. From the second day, the longer the samples are socked, the more hydrophobic the samples will be.

4.4. Fluid Distribution. Four core samples (a, b, c, and d) are used for the NMR experiment. The NMR T2 spectrum of a saturated sample is classified according to the number of peaks: unimodal, bimodal, and trimodal for one, two, and three peaks, respectively. T2 is the transverse relaxation time of $1 \mathrm{H}$, which can be converted to pore size according to Equation (5), so T2 spectrum can be regarded as the pore size distribution. The abscissa of the T2 spectrum represents the pore size, and the vertical axis represents the total pore volume. More details can be found in Coates et al.'s book [58]. As shown in Figure 12, the T2 spectrum showed that under formation water saturation conditions, the original samples $\mathrm{a}$ and $\mathrm{c}$ ( $\mathrm{Y} 0$ in Figures 12(a) and 12(c)) displayed a unimodal distribution. Meanwhile, the original samples $\mathrm{b}$ and $\mathrm{d}(\mathrm{Y} 0$ in Figures 12(b) and 12(d)) showed a bimodal distribution. 
Note that Y0 refers to the original sample and Y1, Y2, Y4, and Y8 represent the samples soaked in slick water for 1, 2, 4, and 8 days, respectively.

Different pore types have been classified by Wang et al. [59] by utilizing NMR combined with centrifugation, while according to the classification method of Yao et al. [32, 60], the left peak of the T2 spectrum corresponds to the adsorption pores, which are mainly micropores, and the right peak corresponds to the seepage pores, which are mainly macropores and fractures. For the samples soaked in slick water, the adsorption pores decreased continuously with time from Y0 to Y2, and the spectrum area also decreased (Figures 12(a) and $12(\mathrm{c})$ ), which indicated that the number of pores decreased after two days of soaking. The original saturated sample (Y0 in Figures 12(b) and 12(d)) had a bimodal distribution, and the peak of the seepage pores was smaller than the peak of the adsorption pores. The change of T2 spectrum with saturation time in Figures 12(b) and 12(d) is similar to that in Figures 12(a) and 12(c). However, the peak of the seepage pores disappeared after the first day of saturation in Figures 12(b) and 12(d), which is due to the swelling of clay minerals blocking the pores.

It was found that when samples were saturated with slick water for the first two days, the peak of the adsorption pores in Figure 12 became smaller, and the bimodal structure disappeared in Figures 12(b) and 12(d). The reason is that the slick water first enters the micropores due to capillary force, and the swelling of clay minerals then blocked the pores. As a result, water cannot enter pores, causing the peak of the seepage pores (macropores) to disappear. Samples were saturated in slick water for two to eight days; the adsorption pores and the seepage pores both increased gradually with time, which is because as the soaking time increased, the swelling of clay minerals with water became stable, and the chemical reaction between slick water and the minerals dominated (Equations (7) and (8)).

\section{Conclusions}

We studied the influence of fracturing fluid (slick water) soaking on pore structure and wettability, and we focused on the impacts of soaking time. Different experimental methods were used to observe the pore structure and wettability, including NMR, LP- $\mathrm{N}_{2} \mathrm{GA}$, and contact angle measurement. The following practical conclusions can be drawn from our study:

(1) According to the IUPAC classification of pore types, being soaked in slick water will not change the pore shape of the shale sample. However, the irregularity and complexity of the pores will be changed, especially the pores with $\mathrm{PD}>4 \mathrm{~nm}$. As the increase of soaking time, the pore complexity and irregularity will decrease, facilitating fluid flow

(2) The influence of slick water on pore structure mainly includes mineral dissolution and swelling. And we found that mineral dissolution and swelling exist at the same time, and the strength of them at different soaking times is different, the mineral dissolution dominates in the first 6 hours, after that swelling effect dominates, and the mineral dissolution dominates again after the sample soaked for 96 hours. As a result, SSA and PD will also change as soaking time increases, leading to the change in the adsorption/ desorption capacity and flow of shale gas

(3) The shale matrix is most hydrophilic on the second day of being soaked in the slick water. From the second day, the longer the samples are socked, the more hydrophobic the shale matrix will be, which means that the flow of gas within the pores will suffer less resistance from the liquid after being soaked in the slick water for a longer time

\section{Data Availability}

Data are available on request.

\section{Conflicts of Interest}

The authors declare that they have no conflicts of interest.

\section{Acknowledgments}

This research was funded by the National Major Science and Technology Projects of China (No. 2017ZX05009-005).

\section{References}

[1] S. Jiang, Z. Xu, Y. Feng et al., "Geologic characteristics of hydrocarbon-bearing marine, transitional and lacustrine shales in China," Journal of Asian Earth Sciences, vol. 115, pp. 404-418, 2016.

[2] M. Gasparik, A. Ghanizadeh, P. Bertier, Y. Gensterblum, S. Bouw, and B. M. Krooss, "High-pressure methane sorption isotherms of black shales from the Netherlands," Energy and Fuels, vol. 26, no. 8, pp. 4995-5004, 2012.

[3] H. Huang, W. Sun, F. Xiong et al., "A novel method to estimate subsurface shale gas capacities," Fuel, vol. 232, pp. 341-350, 2018.

[4] L. CHEN, Z. JIANG, K. LIU, F. GAO, and P. WANG, “A combination of $\mathrm{N} 2$ and $\mathrm{CO} 2$ adsorption to characterize nanopore structure of organic-rich lower Silurian shale in the Upper Yangtze platform, South China: implications for shale gas sorption capacity," Acta Geologica Sinica - English Edition, vol. 91, no. 4, pp. 1380-1394, 2017.

[5] L. Chen, Z. Jiang, S. Jiang et al., "Nanopore structure and fractal characteristics of lacustrine shale: implications for shale gas storage and production potential," Nanomaterials, vol. 9, no. 3, p. $390,2019$.

[6] F. Xiong, Z. Jiang, P. Li et al., "Pore structure of transitional shales in the Ordos Basin, NW China: effects of composition on gas storage capacity," Fuel, vol. 206, pp. 504-515, 2017.

[7] L. Chen, Z. Jiang, K. Liu, P. Wang, F. Gao, and T. Hu, "Application of low-pressure gas adsorption to nanopore structure characterisation of organic-rich lower Cambrian shale in the Upper Yangtze Platform, South China," Australian Journal of Earth Sciences, vol. 64, no. 5, pp. 653-665, 2017. 
[8] R. G. Loucks, R. M. Reed, S. C. Ruppel, and U. Hammes, "Spectrum of pore types and networks in mudrocks and a descriptive classification for matrix-related mudrock pores," American Association of Petroleum Geologists Bulletin, vol. 96, no. 6, pp. 1071-1098, 2012.

[9] H. Wu, Y. Yao, D. Liu, and C. Cui, "An analytical model for coalbed methane transport through nanopores coupling multiple flow regimes," Journal of Natural Gas Science and Engineering, vol. 82, p. 103500, 2020.

[10] J. F. W. Gale, R. M. Reed, and J. Holder, "Natural fractures in the Barnett Shale and their importance for hydraulic fracture treatments," American Association of Petroleum Geologists Bulletin, vol. 91, no. 4, pp. 603-622, 2007.

[11] T. T. Palisch, M. C. Vincent, and P. J. Handren, "Slickwater fracturing: food for thought," in Paper presented at the SPE Annual Technical Conference and Exhibition, vol. 4, pp. 2195-2214, Denver, Colorado, USA, 2008.

[12] G. A. Al-Muntasheri, "A critical review of hydraulic-fracturing fluids for moderate- to ultralow- permeability formations over the last decade," SPE Production \& Operations, vol. 29, no. 4, pp. 243-260, 2014.

[13] P. Kaufman, G. S. Penny, C. Chemical, J. Paktinat, and U. Well, "Critical evaluation of additives used in shale slickwater fracs," Society of Petroleum Engineers, vol. 61, pp. 1618,2008

[14] A. A. Aderibigbe and R. H. Lane, "Rock/fluid chemistry impacts on shale fracture behavior," in Paper presented at the SPE International Symposium on Oilfield Chemistry, vol. 2, pp. 680-689, The Woodlands, Texas, USA, 2013.

[15] M. G. Karfakis and M. Akram, "Effects of chemical solutions on rock fracturing," International Journal of Rock Mechanics and Mining Sciences, vol. 30, no. 7, pp. 1253-1259, 1993.

[16] W. Yuan, Z. Pan, X. Li et al., "Experimental study and modelling of methane adsorption and diffusion in shale," Fuel, vol. 117, pp. 509-519, 2014.

[17] M. Dieterich, B. Kutchko, and A. Goodman, "Characterization of Marcellus Shale and Huntersville Chert before and after exposure to hydraulic fracturing fluid via feature relocation using field- emission scanning electron microscopy," Fuel, vol. 182, pp. 227-235, 2016.

[18] C. Xu, Y. Kang, Z. You, and M. Chen, "Review on formation damage mechanisms and processes in shale gas reservoir: known and to be known," Journal of Natural Gas Science and Engineering, vol. 36, pp. 1208-1219, 2016.

[19] V. Marcon, C. Joseph, K. E. Carter et al., "Experimental insights into geochemical changes in hydraulically fractured Marcellus Shale," Applied Geochemistry, vol. 76, pp. 36-50, 2017.

[20] M. Ali and B. Hascakir, "Water/rock interaction for Eagle ford, marcellus, Green river, and Barnett shale samples and implications for hydraulic-fracturing-fluid engineering," SPE Journal, vol. 22, no. 1, pp. 162-171, 2017.

[21] D. M. Jarvie, R. J. Hill, T. E. Ruble, and R. M. Pollastro, "Unconventional shale-gas systems: the Mississippian Barnett Shale of north-central Texas as one model for thermogenic shale-gas assessment," American Association of Petroleum Geologists Bulletin, vol. 91, no. 4, pp. 475-499, 2007.

[22] J. Kim, A. M. Gomaa, H. Zhang, and S. G. Nelson, "Novel evaluation method of surfactant and clay inhibitor performance on fracturing fluid recovery for Eagle Ford and mancos outcrop shale cores using NMR technique," in Proceedings of the SPE
International Formation Damage Control Symposium Proceedings, pp. 567-578, Lafayette, Louisiana, USA, 2016.

[23] J. Pedlow and M. Sharma, "Changes in shale fracture conductivity due to interactions with water-based fluids," in Proceedings of the Society of Petroleum Engineers-SPE Hydraulic Fracturing Technology Conference, vol. 2014, pp. 134-152, The Woodlands, Texas, USA, 2014.

[24] M. E. Chenevert, "Shale alteration by water adsorption," Journal of Petroleum Technology, vol. 22, no. 9, pp. 1141-1148, 1970.

[25] S. Maghrabi, D. Kulkarni, K. Teke, S. D. Kulkarni, and D. Jamison, "Neural-net modeling of shale-swelling behavior in aqueous drilling fluids," in Proc. SPE/IADC Middle East Drill. Technol. Conf. Exhib, pp. 206-216, Dubai, UAE, 2013.

[26] W. Wu and M. M. Sharma, "Acid fracturing in shales: effect of dilute acid on properties and pore structure of shale," SPE Production \& Operations, vol. 32, no. 1, pp. 51-63, 2017.

[27] F. Civan, "Temperature dependence of wettability related rock properties correlated by the Arrhenius equation," Petrophysics, vol. 45, pp. 350-362, 2004.

[28] Z. Sun, H. Zhang, Z. Wei et al., "Effects of slick water fracturing fluid on pore structure and adsorption characteristics of shale reservoir rocks," Journal of Natural Gas Science and Engineering, vol. 51, pp. 27-36, 2018.

[29] Y. Yuan, R. Rezaee, M. Verrall, S.-Y. Hu, J. Zou, and N. Testmanti, "Pore characterization and clay bound water assessment in shale with a combination of NMR and lowpressure nitrogen gas adsorption," International Journal of Coal Geology, vol. 194, no. 1, pp. 11-21, 2018.

[30] G. Mao, F. Lai, Z. Li, H. Wei, and A. Zhou, "Characteristics of pore structure of tight gas reservoir and its influence on fluid distribution during fracturing," Journal of Petroleum Science and Engineering, vol. 193, p. 107360, 2020.

[31] S. Nemat-Nasser and M. Taya, "On effective moduli of an elastic body containing periodically distributed voids," Quarterly of Applied Mathematics, vol. 39, no. 1, pp. 43-59, 1981.

[32] Y. Yao and D. Liu, "Comparison of low-field NMR and mercury intrusion porosimetry in characterizing pore size distributions of coals," Fuel, vol. 95, pp. 152-158, 2012.

[33] A. Roslin, D. Pokrajac, and Y. Zhou, "Cleat structure analysis and permeability simulation of coal samples based on microcomputed tomography (micro-CT) and scan electron microscopy (SEM) technology," Fuel, vol. 254, p. 115579, 2019.

[34] H. Wu, Y. Zhou, Y. Yao, and K. Wu, "Imaged based fractal characterization of micro-fracture structure in coal," Fuel, vol. 239, pp. 53-62, 2019.

[35] A. Roslin, D. Pokrajac, and Y. Zhou, "Permeability upscaling using the cubic law based on the analysis of multiresolution micro computed tomography images of intermediate rank coal," Energy and Fuels, vol. 33, no. 9, pp. 8215-8221, 2019.

[36] H. Lemmens and D. Richards, "4 Multiscale imaging of shale samples in the scanning electron microscope," AAPG Memoir, vol. 102, pp. 27-35, 2013.

[37] T. Nix and S. Feist-Burkhardt, "New methods applied to the microstructure analysis of Messel oil shale: confocal laser scanning microscopy (CLSM) and environmental scanning electron microscopy (ESEM)," Geological Magazine, vol. 140, no. 4, pp. 469-478, 2003.

[38] J. Bahadur, A. P. Radlinski, Y. B. Melnichenko, M. Mastalerz, and A. Schimmelmann, "Small-angle and ultrasmall-angle neutron scattering (SANS/USANS) study of New Albany 
shale: a treatise on microporosity," Energy and Fuels, vol. 29, no. 2, pp. 567-576, 2015.

[39] Z. Li, Z. Qi, X. Shen, R. Hu, R. Huang, and Q. Han, "Research on quantitative analysis for nanopore structure characteristics of shale based on NMR and NMR cryoporometry," Energy and Fuels, vol. 31, no. 6, pp. 5844-5853, 2017.

[40] M. Tan, K. Mao, X. Song, X. Yang, and J. Xu, "NMR petrophysical interpretation method of gas shale based on core NMR experiment," Journal of Petroleum Science and Engineering, vol. 136, pp. 100-111, 2015.

[41] H. Wu, Y. Yao, Y. Zhou, and F. Qiu, "Analyses of representative elementary volume for coal using X-ray $\mu$-CT and FIBSEM and its application in permeability predication model," Fuel, vol. 254, p. 115563, 2019.

[42] Z. Li, D. Liu, Y. Cai, Y. Wang, and J. Teng, "Adsorption pore structure and its fractal characteristics of coals by $\mathrm{N}_{2}$ adsorption/desorption and FESEM image analyses," Fuel, vol. 257, p. 116031, 2019.

[43] U. Kuila and M. Prasad, "Specific surface area and pore-size distribution in clays and shales," Geophysical Prospecting, vol. 61, no. 2, pp. 341-362, 2013.

[44] C. R. Clarkson, N. Solano, R. M. Bustin et al., "Pore structure characterization of North American shale gas reservoirs using USANS/SANS, gas adsorption, and mercury intrusion," Fuel, vol. 103, pp. 606-616, 2013.

[45] B. B. Mandelbrot and J. A. Wheeler, "The fractal geometry of nature," American Journal of Physics, vol. 51, no. 3, pp. 286287, 1983.

[46] Y. Yao, D. Liu, D. Tang, S. Tang, and W. Huang, "Fractal characterization of adsorption-pores of coals from North China: an investigation on $\mathrm{CH}_{4}$ adsorption capacity of coals," International Journal of Coal Geology, vol. 73, no. 1, pp. 27-42, 2008.

[47] F. Yang, Z. Ning, and H. Liu, "Fractal characteristics of shales from a shale gas reservoir in the Sichuan Basin, China," Fuel, vol. 115, pp. 378-384, 2014.

[48] H. Qi, J. Ma, and P. Wong, "Adsorption isotherms of fractal surfaces," ASp, vol. 206, no. 1-3, pp. 401-407, 2002.

[49] Y. Yin, "Adsorption isotherm on fractally porous materials," Langmuir, vol. 7, no. 2, pp. 216-217, 1991.

[50] S. Zhang, S. Tang, D. Tang, Z. Pan, and F. Yang, “The characteristics of coal reservoir pores and coal facies in Liulin district, Hedong coal field of China," Acta Geologica Sinica, vol. 81, no. 2, pp. 117-127, 2010.

[51] A. Li, W. Ding, J. He, P. Dai, S. Yin, and F. Xie, "Investigation of pore structure and fractal characteristics of organic-rich shale reservoirs: a case study of Lower Cambrian Qiongzhusi formation in Malong block of eastern Yunnan Province, South China," Marine and Petroleum Geology, vol. 70, pp. 46-57, 2016.

[52] D. Avnir and M. Jaroniec, "An isotherm equation for adsorption on fractal surfaces of heterogeneous porous materials," Langmuir, vol. 5, no. 6, pp. 1431-1433, 1989.

[53] J. Liu, Y. Yao, D. Liu, Y. Cai, and J. Cai, "Comparison of pore fractal characteristics between marine and continental shales," Fractals, vol. 26, no. 2, pp. 1840016-1840016, 2018.

[54] J. C. Groen, L. A. A. Peffer, and J. Pérez-Ramírez, "Pore size determination in modified micro- and mesoporous materials. Pitfalls and limitations in gas adsorption data analysis," Microporous and Mesoporous Materials, vol. 60, no. 1-3, pp. 1-17, 2003.
[55] Y. Cai, D. Liu, Z. Pan, Y. Yao, J. Li, and Y. Qiu, "Petrophysical characterization of Chinese coal cores with heat treatment by nuclear magnetic resonance," Fuel, vol. 108, pp. 292-302, 2013.

[56] K. S. W. Sing, "Reporting physisorption data for gas/solid systems with special reference to the determination of surface area and porosity (Recommendations 1984)," Pure and Applied Chemistry, vol. 57, no. 4, pp. 603-619, 1985.

[57] F. Rouquerol, J. Rouquerol, and K. Sing, Adsorption by Powders and Porous Solids: Principles, Methodology and Applications, Academic Press, London, 1999.

[58] G. Coates, L. Xiao, and M. Prammer, NMR logging: principles and applications, vol. 234, Haliburton Energy Services, 1999.

[59] F. Wang, K. Yang, and J. Cai, "Fractal characterization of tight oil reservoir pore structure using nuclear magnetic resonance and mercury intrusion Porosimetry," Fractals, vol. 26, no. 2, p. 1840017, 2018.

[60] Y. Yao, D. Liu, Y. Che, D. Tang, S. Tang, and W. Huang, "Petrophysical characterization of coals by low-field nuclear magnetic resonance (NMR)," Fuel, vol. 89, no. 7, pp. 1371-1380, 2010. 